\title{
Rare variants increase the risk of severe COVID-19
}

\section{Evidence is mounting that rare loss-of-function variants in the TLR7 gene predispose men with no medical history to severe forms of COVID-19.}

\author{
FRANK L VAN DE VEERDONK AND MIHAI G NETEA
}

Related research article Fallerini C, Daga S, Mantovani S, Benetti E, Picchiotti N, Francisci D, Paciosi F, Schiaroli E, Baldassarri M, Fava F, Palmieri M, Ludovisi S, Castelli F, Quiros-Roldan E, Vaghi M, Rusconi S, Siano M, Bandini M, Spiga O, Capitani K, Furini S, Mari F, GEN-COVID Multicenter Study, Renieri A, Mondelli MU, Frullanti E. 2021. Association of Toll-like receptor 7 variants with life-threatening COVID-19 disease in males: findings from a nested casecontrol study. elife 10:e67569. doi: 10. 7554/eLife.67569 (c) Copyright van de Veerdonk and Netea. This article is distributed under the terms of the Creative Commons Attribution License, which permits unrestricted use and redistribution provided that the original author and source are credited.

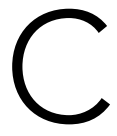
OVID-19 is a disease that does not strike equally: while most individuals will experience no or only mild respiratory symptoms, a minority - including young patients in their 20 s or 30 s - will develop severe pneumonia and acute respiratory distress syndrome, sometimes resulting in death. Identifying the underlying factors that predispose to severe COVID-19, especially in young individuals, is crucial to initiate preventive measures and design treatment strategies for at-risk patients.

Accumulating evidence suggests that rare loss-of-function mutations in a single gene known as TLR7 could predispose men under 50 without known risk factors to severe COVID-19. TLR7 codes for a Toll-like receptor that can recognise single-strand RNA present in viruses such as SARS-CoV-2, the agent responsible for
COVID-19. Once activated, the receptor helps to switch on the immune response, triggering the production of pro-inflammatory molecules and the release of type I and II interferon proteins that regulate the activity of the immune system.

Now, in eLife, Alessandra Renieri and colleagues at the University of Siena and a number of other institutes in Italy - including Chiara Fallerini, Sergio Daga, and Stefania Mantovani as joint first authors - report five cases of men (three under 50, and two in their mid-60s) with severe COVID-19 who carry rare TLR7 variants (Fallerini et alo, 2021). These data validate and extend two other studies we have been involved in: one highlights two sets of two young brothers (median age of 26) carrying a rare TLR7 variant who suffered from severe COVID-19 (van der Made et al., 2020); the other identified TLR7 variants in a selected group of COVID-19 patients (Solanich et al., submitted to medRxiv). In total, these three reports describe eight rare TLR7 variants in 12 male patients with no medical history who still developed severe COVID-19. We are therefore more confident with suggesting that variants of this single gene are responsible for an important proportion of risk factor for severe COVID-19 in men under 50.

Functional studies have started to shed light on the mechanism by which TLR7 variants can lead to severe COVID-19. This work shows that the variants disrupt the production of type I and type II interferon after stimulation of the TLR7 receptor, which suggests that the mutations lead to a loss-of-function in the antiviral response to SARS-CoV-2 (van der Made et al., 
2020). However, Fallerini et al. show that some of the rare TLR7 variants only have a marginal effect on the release of type I interferon, indicating that additional pathways influence the body's defence against SARS-CoV-2.

Given these studies, it is somewhat surprising that a global initiative using exome or genome sequencing in 657 patients with severe COVID19 did not report TLR7 variants, focusing instead on the pathways that allow the recognition of viral infections such as influenza. This initiative identified defects in the TLR3 and IRF7 pathway that could be responsible for up to $3.5 \%$ of patients with severe COVID-19 (Zhang et al., 2020). The field is now anxiously waiting for potential TLR7 variants to be identified in this large dataset as well. Indeed, Fallerini et al. suggest that at least $2 \%$ of severely ill Italian COVID-19 patients have loss of function TLR7 variants, but this percentage could be even higher in other populations.

Since the first report on TLR7 variants in severe COVID-19, diagnostic pipelines have been developed to discover such mutations. Being aware that this monogenetic factor predisposes young men to severe outcomes has several consequences. First, families of patients with TLR7 variants could be screened, and individuals fast-tracked for vaccination if identified as carriers. Second, unvaccinated carriers of rare TLR7 variants that predispose to severe COVID19 could benefit from prophylactic interferon gamma treatment, similar to that given to patients with chronic granulomatous disease to prevent severe infection (The International Chronic Granulomatous Disease Cooperative Study Group, 1991; Marciano et al., 2004). Third, patients with these variants should be admitted to hospital earlier, be monitored more closely for complications, and be treated more aggressively once they become critically ill. Indeed, there is an argument for screening all men under 50 who have been admitted to intensive care (and their families) for the TLR7 variants. Together, these measures might have a dramatic impact on clinical outcome.
Frank $L$ van de Veerdonk is in the Department of Internal Medicine, Radboudumc Center for Infectious Diseases, Nijmegen, The Netherlands

frank.vandeveerdonk@radboudumc.nl (iD) https://orcid.org/0000-0002-1121-4894

Mihai G Netea is in the Department of Internal Medicine, Radboudumc Center for Infectious Diseases, Nijmegen, The Netherlands and the Department of Immunology and Metabolism, Life and Medical Sciences Institute, University of Bonn, Bonn, Germany

Competing interests: The author declares that no competing interests exist.

Published 23 March 2021

\section{References}

Fallerini C, Daga S, Mantovani S, Benetti E, Picchiotti $N$, Francisci D, Paciosi F, Schiaroli E, Baldassarri M, Fava F, Palmieri M, Ludovisi S, Castelli F, QuirosRoldan E, Vaghi M, Rusconi S, Siano M, Bandini M, Spiga O, Capitani K, et al. 2021. Association of Tolllike receptor 7 variants with life-threatening COVID-19 disease in males: findings from a nested case-control study. eLife 10:e67569. DOI: https://doi.org/10.7554/ eLife.67569, PMID: 33650967

Marciano BE, Wesley R, De Carlo ES, Anderson VL, Barnhart LA, Darnell D, Malech HL, Gallin JI, Holland SM. 2004. Long-term interferon-gamma therapy for patients with chronic granulomatous disease. Clinical Infectious Diseases 39:692-699. DOI: https://doi.org/ 10.1086/422993, PMID: 15356785

The International Chronic Granulomatous Disease Cooperative Study Group. 1991. A controlled trial of interferon gamma to prevent infection in chronic granulomatous disease. New England Journal of Medicine 324:509-516. DOI: https://doi.org/10.1056/ NEJM199102213240801

van der Made Cl, Simons A, Schuurs-Hoeijmakers J, van den Heuvel G, Mantere T, Kersten S, van Deuren RC, Steehouwer M, van Reijmersdal SV, Jaeger M, Hofste T, Astuti G, Corominas Galbany J, van der Schoot $V$, van der Hoeven $\mathrm{H}$, Hagmolen of ten Have W, Klijn E, van den Meer C, Fiddelaers J, de Mast Q, et al. 2020. Presence of genetic variants among young men with severe COVID-19. JAMA 324:663-673. DOI: https://doi.org/10.1001/jama.2020.13719 Zhang Q, Bastard P, Liu Z, Le Pen J, Moncada-Velez M, Chen J, Ogishi M, Sabli IKD, Hodeib S, Korol C, Rosain J, Bilguvar K, Ye J, Bolze A, Bigio B, Yang R, Arias AA, Zhou Q, Zhang Y, Onodi F, et al. 2020. Inborn errors of type I IFN immunity in patients with life-threatening COVID-19. Science 370:eabd4570. DOI: https://doi.org/10.1126/science.abd4570, PMID: 32972995 